\title{
A PRODUÇÃO DO CONHECIMENTO NA PSICOLOGIA SOCIAL BRASILEIRA: UM ESTUDO DESCRITIVO A PARTIR DA REVISTA PSICOLOGIA \& SOCIEDADE, 1986-1992
} KNOWLEDGE PRODUCTION IN BRAZILIAN SOCIAL PSYCHOLOGY: A DESCRIPTIVE STUDY FROM THE JOURNAL OF PSYCHOLOGY \& SOCIETY, 1986-1992

\author{
Robson Nascimento da Cruz e Cornelis Johannes van Stralen \\ Universidade Federal de Minas Gerais, Belo Horizonte, Brasil
}

\section{RESUMO}

Com o intuito de auxiliar na compreensão da história recente da Psicologia Social brasileira, apresentamos a primeira parte de pesquisa que objetivou descrever alguns aspectos que perpassam sua organização científica e social, o que se deu a partir de um dos seus principais veículos de comunicação, o periódico Psicologia \& Sociedade: Revista da Associação Brasileira de Psicologia Social (ABRAPSO). Para isso, analisamos os trabalhos publicados entre os anos de 1986 e 1992. Assim, o total de 277 trabalhos, distribuídos em 10 revistas, constituiu nossa fonte de pesquisa. A origem institucional e geográfica dos autores, o padrão de autoria, o tipo e as temáticas dos trabalhos publicados, a metodologia e os locais de realização das investigações e intervenções, foram as informações examinadas. Por fim, a identificação tanto das transformações quanto de padrões de funcionamento da área, e alguns de seus possíveis determinantes, são apresentados.

Palavras-chave: história da psicologia social brasileira; psicologia social; história da psicologia social; comunidade científica.

\begin{abstract}
With the objective of helping the comprehension of the recent Brazilian Social Psychology history, we present the first part of the survey, aimed at describing some aspects that go through its scientific and social organization, which happened from one of its main means of communication, the periodical Psicologia \& Sociedade (Psychology \& Society): a magazine from the Brazilian Association of Social Psychology (ABRAPSO). For that, we analyzed the works published between the years 1986 and 1992. Thus, the total of 277 works, distributed in 10 magazines, constituted our survey source. The institutional and geographic origin of the authors, the authorship pattern, the type and themes of the published works, the methodology and the places where investigations and interventions took place were examined. Finally, the identification of the transformations as well as the patterns of the area functioning, and some of its determiners, are presented.
\end{abstract}

Keywords: history of brazilin social psychology; social psychology; history of social psychology; scientific community.

Embora prelúdios da crise da Psicologia Social sejam identificados já no final do século XIX (Faye, 2005), é na segunda metade do século XX que a emergência de tal crise torna-se evidente na literatura da área. Assim, nas décadas de 1960, 1970 e 1980 na América do Norte, Europa, Ásia e América Latina, surge uma série de discussões acerca dos limites metodológicos, epistemológicos e das implicações ideológicas, sociais e políticas da atuação profissional e da produção científica da Psicologia Social (Bonfim,
2003; Elms, 1971; Irwin, 1971; Mitsui, 1986; Molon, 2001; Rodríguez, 1987).

Na América Latina, o movimento de reação, em especial à hegemonia da vertente individualista da Psicologia Social experimental cognitiva americana como referencial teórico e metodológico dos estudos em Psicologia Social, foi um dos desdobramentos dessa crise. No contexto brasileiro, o surgimento da Associação Brasileira de Psicologia Social (ABRAPSO), em 1980, como organização contrária a essa forma de produção 
científica, é um dos principais marcos da história recente da Psicologia Social brasileira. Desde então, o número crescente de disciplinas, cursos de pós-graduação e publicações nacionais caracterizam o desenvolvimento de uma nova perspectiva em Psicologia Social no Brasil (Bomfim, 1989-1990).

Também como uma das consequências dessa mudança, a Psicologia Social no Brasil passa a desenvolver, nessas últimas três décadas, uma pluralidade de concepções metodológicas, epistemológicas, políticas e éticas que influenciam diretamente a formação, atuação e produção científica do psicólogo social. Com isso, muitas das discussões que permeiam a Psicologia Social nas últimas décadas modificaram-se; algumas foram superadas, outras continuam na pauta das discussões e várias outras começaram a fazer parte dos novos debates que perpassam o campo.

Tendo em vista essas transformações, propusemo-nos a realizar um estudo descritivo da produção de conhecimento na Psicologia Social brasileira, com o intuito de compreender parte do desenvolvimento da área nas últimas décadas.

Sabe-se que uma área do conhecimento como a Psicologia Social não pode ser restrita apenas ao seu conteúdo publicado em livros ou revistas científicas. No entanto, devido à necessidade de delimitação de um tema que fosse, ao mesmo tempo, relevante para a comunidade científica e dentro dos nossos limites de trabalho, optou-se pela análise de um periódico científico - a revista Psicologia \& Sociedade: Revista da Associação Brasileira de Psicologia Social - para tal empreendimento. Essa escolha teve como fundamento o importante papel que esse periódico exerce na constituição da Psicologia Social a partir da década de 1980, sendo ele, na verdade, um dos produtos que caracterizam as mudanças da Psicologia Social no contexto brasileiro.

Assim, buscamos uma caracterização da produção científica divulgada na Revista Psicologia \& Sociedade, com atenção especial para a descrição dos seguintes elementos: os centros e núcleos de desenvolvimento de Psicologia Social no Brasil; o perfil dos autores e o padrão de autoria; as temáticas dos trabalhos veiculados e as características metodológicas das pesquisas e intervenções publicadas.

Os resultados que se seguem representam o período de 1986 a 1992 e compõem o que denominamos de primeira fase da revista Psicologia \& Sociedade. A escolha por essa denominação e delimitação temporal, como será exposto, foi fundamentada nas diferenças de formato e na organização da revista ao longo de sua existência.

\section{Contextualização da primeira fase da revista Psicologia \& Sociedade: a busca pela legitimidade de uma nova perspectiva em Psicologia Social}

A fundação de sociedades científicas, a criação de periódicos e a implantação de novas disciplinas nos currículos acadêmicos geralmente estão associadas ao momento histórico em que um grupo de pesquisadores adota uma nova perspectiva científica (Kuhn, 1962). No caso da Psicologia Social brasileira, o surgimento da ABRAPSO, a criação de meios de comunicação científica por essa associação e a alteração nos currículos de Psicologia Social indicam a formação e aceitação de uma nova tendência em Psicologia Social emergindo no Brasil.

A comunicação científica desempenha papel fundamental nesses momentos de mudança em uma ciência (Meadows, 1999). No caso do surgimento da ABRAPSO, criar meios de divulgação de uma nova produção de conhecimento em Psicologia Social no Brasil constitui-se em um dos seus principais objetivos. No primeiro estatuto dessa associação, essa posição é bem definida:

\begin{abstract}
ABRAPSO TEM POR FINALIDADE: Garantir e desenvolver as relações entre pessoas dedicadas ao estudo, ensino, investigação e aplicação da Psicologia em uma perspectiva social no Brasil. Propiciar a difusão e o intercâmbio de informações sobre o desenvolvimento do conhecimento e prática da Psicologia Social. Organizar conferências e cursos e promover a publicação de trabalhos de interesse para o desenvolvimento da Psicologia Social. Promover a integração da Psicologia com outras áreas do conhecimento que atuem em uma perspectiva social crítica. Incentivar e apoiar institucionalmente o desenvolvimento de ações no campo social e comunitário (ABRAPSO, 1995, p. 1).
\end{abstract}

A publicação de livros como $O$ que é Psicologia Social?, de Silvia Lane, em 1981 e Psicologia Social: o homem em movimento, organizado por Silvia Lane e Wanderley Codo, em 1984, é exemplar das novas tendências teóricas e práticas formuladas por uma parcela significativa dos psicólogos sociais brasileiros, a partir do início dos anos 80.

Nesse momento, a criação de um periódico científico desempenhou a função de legitimar e fortalecer a identidade desse novo grupo. No caso da ABRAPSO, isso ocorre, inicialmente, por meio de seu boletim informativo, distribuído aos associados, nos primeiros anos da década de 80, e redefinido a partir do ano de 1986, quando é transformado na revista Psicologia \& Sociedade.

Embora não se esteja propondo aqui a ideia de que houve adoção ou estabelecimento de um paradigma aos moldes kuhnianos, nota-se nesse momento a existência de um padrão histórico característico de momentos de 
mudanças significativas na organização social de uma ciência. Em particular, a fundação de sociedades de especialistas que reivindicam um lugar especial no campo científico. O que reflete, como veremos adiante, a composição de um novo grupo científico, com novos conceitos, métodos, campos de atuação e objetivos políticos e éticos.

Tal perspectiva é indicada no primeiro editorial dessa revista, sinalizando que a mudança de um boletim para uma revista era produto da necessidade de ampliação da divulgação do conhecimento produzido pela área, sendo o aumento do número de associados e de participantes nos encontros da ABRAPSO a principal justificativa para a criação de uma revista. Ao mesmo tempo é destacado que a publicação de uma revista foi um passo importante para a consolidação dessa associação (Caniato, 1986).

Outra característica marcante da sua primeira fase é que a revista Psicologia \& Sociedade apresenta-se mais como uma espécie de anais, em geral com trabalhos completos de encontros regionais e nacionais da ABRAPSO, do que como uma revista científica nos moldes tradicionais. Tal informação torna-se relevante à medida que são percebidas relações entre o contexto de produção e as características dessa produção, algo que também será apontado ao longo deste trabalho.

Em relação a questões de ordem política da organização da área, foram encontradas poucas informações. Em geral, os editoriais apresentaram esclarecimentos relativos à origem e às temáticas dos trabalhos, agradecimentos e outros informes básicos. Na edição especial de 1992, entretanto, quando se comemora o décimo número da revista, junto com seu editorial é publicado o boletim informativo de 1992, que indica algumas questões críticas da organização da ABRAPSO naquele momento, em especial problemas de comunicação, tanto interna quanto externa.

\section{Desafios...}

O ano novo [1992] recoloca os desafios que o ano findo nos havia legado: reafirmar a posição da ABRAPSO como associação científica. Envidamos esforços em duas direções, para isto: a energização orgânica (rearticulação das estruturas) e a busca de visibilização da nossa produção, via publicação da Revista, segundo decisão da última Assembléia Geral.

Estes dois caminhos descortinam para nós, a impossibilidade de continuarmos ilhados, exercendo nossas responsabilidades solitariamente, solidão à qual nos relega a falta de resposta das regionais. Duas notícias, porém, trazem bons ventos para nós: São Paulo prepara com garra e competência um Encontro Regional sobre “A Psicologia Social e a Questão da Cidadania" para maio próximo e o Rio está criando um colegiado pro- visório para sua representação, com colegas de várias universidades e do sindicado.

Entretanto, no resto do país, fez-se o silêncio. Não obtivemos nenhum retorno sobre a atualização da lista de sócios que enviamos aos representantes, a cobrança de anuidades, e nem sequer sabemos se o último boletim foi por eles distribuído. Ou seja, como vai a ABRAPSO no resto do Brasil? Esperemos que ela não tenha desaparecido do horizonte dos/as associados/as. A responsabilidade da comunicação compartilhada depende de todos nós.

E por falar em comunicação, desejamos inaugurar uma inversão mais radical do seu sentido: não apenas a Direção Nacional fornecerá a matéria para o Boletim, o que coloca o intercâmbio sempre em mão única. Queremos a mão dupla, ou melhor, múltipla: de agora em diante, aguardaremos notícias das regiões para compor o boletim. E a primeira delas, depois da de São Paulo, está em relação à Revista. Após tentativas infrutíferas junto a editoras do Rio e São Paulo (Rosa dos Tempos e Cortez), concluímos que é impossível levarmos adiante a resolução coletiva sozinhos. Assim, solicitamos aos representantes que pesquisassem as possibilidades de editar a revista localmente e nos informassem até fim de março. São Paulo (mais uma vez) e a Paraíba deram suas respostas, que se encontram mais adiante.

os desafios provenientes da falta de comunicação que permitissem maior agilização continuam: REATAR É PRECISO. (Arruda, Baptista, Nascimento, Rocha-Coutinho \& Jurberb, 1992, p. 3-4)

Essa passagem evidencia a preocupação da diretoria da ABRAPSO (1991-1993) com a comunicação entre e com as regionais. E retoma a necessidade de uma revista que ofereça mais visibilidade à área. Ainda sobre isso, é preciso notar que esse foi o último número da revista no formato de anais dos trabalhos apresentados nos encontros nacionais e regionais da ABRAPSO. Após esse número, ocorre um hiato na publicação, que só é retomada em 1996, quando assume o formato tradicional dos periódicos científicos, ou seja, os trabalhos publicados agora são artigos submetidos ao processo editorial de avaliação cega por pares.

Embora a revista, nessa primeira fase, apresente como principal objetivo publicar trabalhos apresentados nos encontros da ABRAPSO, foi possível observar que diversos deles eram provenientes de outros eventos científicos. Trabalhos apresentados em encontros da Sociedade Brasileira de Psicologia (SBP) e da Sociedade Brasileira para o Progresso da Ciência (SBPC) são exemplos da participação e divulgação da Psicologia Social em outros espaços de divulgação científica. O quadro 1 apresenta a descrição geral dos encontros da ABRAPSO dos quais foram originados os trabalhos que compuseram a revista em sua primeira fase, o que é formulado a partir dos títulos apresentados nas capas e editoriais da revista. 
Cruz, R. N. e van Stralen, C. J. A produção do conhecimento na psicologia social brasileira: um estudo descritivo a partir da revista Psicologia...

Quadro 1 - Distribuição de revistas por ano, classificadas pelo título dos números

\begin{tabular}{|c|c|c|}
\hline Ano & Número & Evento \\
\hline 1986 & 1 & Encontro Psicologia Maringá \\
\hline 1986 & 2 & $\begin{array}{c}6^{\circ} \text { Encontro Regional da ABRAPSO São Paulo - Psicanálise ou Marxismo: } \\
\text { Dilema da Psicologia Social? }\end{array}$ \\
\hline 1987 & 3 & Anais do II Encontro Nacional e II Encontro Mineiro de Psicologia Social \\
\hline 1988 & 4 & Anais do III Encontro Mineiro de Psicologia Social \\
\hline 1988 & 5 & Identidade: Encruzilhada do Homem - evento UFMG /Por uma sociedade sem manicômios \\
\hline $1988 / 1989$ & 6 & Anais do IV Encontro Mineiro de Psicologia Social \\
\hline 1989 & 7 & Anais do IV Encontro Nacional de Psicologia Social \\
\hline $1989 / 1990$ & 8 & $\begin{array}{l}\text { Anais do V Encontro Nacional de Psicologia Social / } \\
\text { Anais do V Encontro Mineiro de Psicologia Social }\end{array}$ \\
\hline 1990/1991 & 9 & $\begin{array}{l}\text { Anais do VI Encontro Nacional de Psicologia Social / } \\
\text { Anais do VI Encontro Mineiro de Psicologia Social }\end{array}$ \\
\hline 1992 & 10 & Anais do VI Encontro Nacional de Psicologia Social \\
\hline
\end{tabular}

Os conselhos editoriais dessa fase foram assim constituídos: representantes do Estado de São Paulo, na primeira e na segunda edição; da terceira à nona edição, representantes de Minas Gerais e, em seu último número, a revista foi organizada por representantes do Estado do Rio de Janeiro (Quadro 2). Aqui é preciso dizer que, diferentemente do modelo atual, o conselho editorial nessa fase da revista desempenha o papel de organizador dos trabalhos que a compõem. Não havia nesse momento a função de avaliação cega por pares como é o caso atualmente. Assim, todos os trabalhos apresentados nos eventos eram publicados.

Quadro 2 - Distribuição dos Conselhos Editoriais da primeira fase da revista (1986 -1992)

\begin{tabular}{ccc}
\hline Ano & Número & Conselho Editorial \\
\hline 1986 & 1 e 2 & $\begin{array}{c}\text { Adalberto Abib Andery } \\
\text { Yvonne Anataitis } \\
\text { Odair Furtado } \\
\text { Brônia Liebsny } \\
\text { Luis Carlos Sampaio }\end{array}$ \\
\hline 1987 & 3 & Elizabeth de Melo Bomfim \\
1988 & 4 e 5 & Elizabeth de Melo Bonfim \\
$1988-1989$ & 6 & Marcos Vieira Silva \\
1989 & 7 & Vânia Carneiro Franco \\
$1989-1990$ & 8 & \\
$1990-1991$ & 9 & Marise Bezerra Jurberg \\
\hline 1992 & 10 & Ângela Arruda \\
& & Luiz Antonio Baptista \\
& & Maria Lívia do Nascimento \\
& & Maria Lúcia Rocha-Coutinho \\
\hline
\end{tabular}

A estrutura dos conselhos editoriais foi relevante, como será visto, para a compreensão, principalmente, de como esses podem estar relacionados à forma como a produção da área se organizou. Isso porque é evidente a relação entre o volume de produção de determinadas regiões e o local onde se encontrava o conselho editorial da revista.

\section{Origem geográfica e institucional dos trabalhos veiculados na primeira fase da revista Psicologia \& Sociedade}

Uma descrição geral da origem regional e institucional dos trabalhos foi nossa primeira tarefa. Para isso, foi elaborada uma espécie de cartografia dos trabalhos publicados nessa fase. A apresentação dessa informação mostra como a origem regional e institucional pode estar relacionada com a produção de conhecimento veiculada na revista. Dessa maneira, buscou-se, primeiramente, identificar a distribuição e a participação geral dos trabalhos, por Estados (Tabela 1).

Representantes de treze estados tiveram seus trabalhos publicados na primeira fase da revista. A primeira informação que sobressai é a diferença, em termos quantitativos, da participação de estados da Região Sudeste em relação aos demais. Mais de $60 \%$ dos trabalhos foram provenientes dessa região. O Estado de Minas Gerais foi o estado que apresentou maior frequência de participação nessa fase, seguido pelos estados do Rio de Janeiro, São Paulo, Paraíba e Espírito Santo.

Ainda em relação à distribuição regional dos trabalhos, foi possível notar que mais da metade dos estados brasileiros - quatorze estados - não participaram dessa fase da revista. No caso da participação internacional, apenas dois países foram identificados: Cuba e França, ambos com apenas um trabalho. 
Tabela 1 - Distribuição das publicações, por estados, na primeira fase da revista (1986 -1992)

\begin{tabular}{ccc}
\hline Estados & Frequência & $\%$ \\
\hline MG & 120 & 44,0 \\
RJ & 38 & 13,9 \\
SP & 29 & 10,6 \\
PB & 14 & 5,1 \\
ES & 13 & 4,8 \\
PR & 9 & 3,3 \\
DF & 7 & 2,6 \\
SC & 6 & 2,2 \\
PA & 6 & 2,2 \\
CE & 5 & 1,8 \\
RS & 5 & 1,8 \\
MS & 1 & 0,4 \\
PE & 1 & 0,4 \\
\hline Internacional & 2 & 0,7 \\
\hline Sem Informação & 21 & 7,7 \\
\hline Total & 277 & 100 \\
\hline
\end{tabular}

É preciso, contudo, relativizar tais considerações acerca das diferenças dos estados, já que essas informações não significam que aqueles estados que não tiveram trabalhos publicados na primeira fase da revista, ou que tiveram um número reduzido de publicações, não possuíssem trabalhos relevantes em Psicologia Social, naquele período. A concentração de trabalhos em determinadas regiões e estados se relacionará, como veremos adiante, a outras informações e é indicativa de um padrão de organização da comunidade científica no Brasil que reflete, em grande medida, diferenças, em particular, das condições socioeconômicas dos estados ausentes nesse momento da revista.

Em relação à distribuição das instituições que figuram na primeira fase da revista, a informação relevante refere-se ao tipo de instituição à qual os autores são vinculados (Tabela 2). Nesse caso, observou-se que grande parte dos trabalhos é oriunda de instituições de ensino superior públicas.

Tabela 2 - Distribuição geral das instituições na primeira fase da revista (1986 -1992)

\begin{tabular}{ccc}
\hline Tipos de Instituição & Frequência & $\%$ \\
\hline Universidade Pública & 20 & 39,2 \\
Universidade Particular & 9 & 17,6 \\
Universidade Estrangeira & 2 & 3,9 \\
Órgão Público & 3 & 5,9 \\
Sem Informação & 17 & 33,3 \\
\hline Total & 51 & 100,0 \\
\hline
\end{tabular}

Ao mesmo tempo, a distribuição das instituições que apresentam trabalhos na primeira fase da revista pode ser visualizada como um reflexo da distribuição regional dos trabalhos (Tabela 3), à exceção da Universidade Federal da Paraíba, a qual não se encontra na região sudeste e apresenta quatorze trabalhos, que representam 5,1\% dos artigos publicados. Essa informação pode ser explicada pela tradição em Psicologia Social daquela instituição e pela existência de um programa de pós-graduação em Psicologia Social desde a década de 1980 .

Tabela 3 - Distribuição de trabalhos por instituição, na primeira fase da revista (1986 -1992)

\begin{tabular}{|c|c|c|}
\hline Instituição & Frequência & $\%$ \\
\hline UFMG & 92 & 33,2 \\
\hline PUC-SP & 17 & 6,1 \\
\hline UFRJ & 17 & 6,1 \\
\hline UFPB & 14 & 5,1 \\
\hline UFES & 13 & 4,7 \\
\hline UERJ & 11 & 4,0 \\
\hline USP & 8 & 2,9 \\
\hline PUC-MG & 8 & 2,9 \\
\hline UEM & 7 & 2,5 \\
\hline UNB & 7 & 2,5 \\
\hline FUNREI-MG & 6 & 2,2 \\
\hline UFPA & 6 & 2,2 \\
\hline UNIFENAS-MG & 6 & 2,2 \\
\hline UFSC & 5 & 1,8 \\
\hline UFC & 5 & 1,8 \\
\hline UFF & 4 & 1,4 \\
\hline PUC-RS & 3 & 1,1 \\
\hline $\begin{array}{c}\text { DELEGACIA DE CRIMES CONTRA } \\
\text { A MULHER(BH) }\end{array}$ & 2 & 0,7 \\
\hline FGV-RJ & 2 & 0,7 \\
\hline PREFEITURA BH & 2 & 0,7 \\
\hline UNICAMP & 2 & 0,7 \\
\hline UFRGS & 2 & 0,7 \\
\hline UEL & 2 & 0,7 \\
\hline PUC-RJ & 2 & 0,7 \\
\hline USP-RP & 1 & 0,4 \\
\hline NEWTON PAIVA & 1 & 0,4 \\
\hline UFPE & 1 & 0,4 \\
\hline FACUL.SENADOR FLAQUER-SP & 1 & 0,4 \\
\hline FIO-CRUZ-RJ & 1 & 0,4 \\
\hline UNIVALI-SC & 1 & 0,4 \\
\hline UNISINOS-RS & 1 & 0,4 \\
\hline UFU & 1 & 0,4 \\
\hline FAFI-BH & 1 & 0,4 \\
\hline UFMS & 1 & 0,4 \\
\hline UNIVERSIDADE HAVANA-CUBA & 1 & 0,4 \\
\hline $\begin{array}{c}\text { ÉCOLE DES HAUTES ÉTUDES EN } \\
\text { SCIENCES SOCIALES-FRANÇA }\end{array}$ & 1 & 0,4 \\
\hline PREFEITURA CAMBUQUIRA-MG & 1 & 0,4 \\
\hline SEM INFORMAÇÃO & 17 & 7,6 \\
\hline TOTAL & 277 & 100,0 \\
\hline
\end{tabular}


Ainda em relação à distribuição das instituições da primeira fase da revista, destaca-se a concentração de mais de $60 \%$ dos trabalhos em sete das trinta e sete instituições identificadas nessa fase. A Universidade Federal de Minas Gerais concentrou 33, $2 \%$ do total de trabalhos. Os possíveis motivos dessa concentração se relacionam ao fato de que sete das dez edições da primeira fase da revista foram organizadas em Minas Gerais e tiveram incluídos, em seu conteúdo, anais dos Encontros Mineiros de Psicologia Social.

\section{Autoria e perfil dos autores}

O segundo tipo de informação volta-se para uma tentativa de buscar, nos padrões de autoria, relações com o contexto de produção dos autores e outras informações tratadas nesta pesquisa. Embora, como veremos, exista uma baixa variabilidade nos padrões de autoria nesta fase da pesquisa, eles serviram de base para avaliar algumas características da área no período analisado.

A primeira fase da revista contou com a participação de 266 autores (Tabela 4). Nessa fase a frequência de participação dos autores é marcada pelo elevado número de autores que publicaram apenas um trabalho, e pelo reduzido número de autores que publicaram mais de dois trabalhos.

Tabela 4 - Frequência de participação dos autores na primeira fase da revista (1986 -1992)

\begin{tabular}{ccc}
\hline $\begin{array}{c}\text { Número de trabalhos } \\
\text { publicados }\end{array}$ & $\begin{array}{c}\text { Frequência de } \\
\text { autores }\end{array}$ & $\%$ \\
\hline 1 & 221 & 83,1 \\
2 & 28 & 10,5 \\
3 & 10 & 3,8 \\
4 & 2 & 0,8 \\
5 & 1 & 0,4 \\
7 & 1 & 0,4 \\
9 & 1 & 0,4 \\
14 & 1 & 0,4 \\
28 & 1 & 0,4 \\
\hline
\end{tabular}

A concentração de um grupo reduzido de autores que publicaram mais de dois trabalhos na primeira fase da revista precisa ser comentada. Nesse caso, os autores estão, em sua maioria, vinculados a instituições do Estado de Minas Gerais e a outras instituições descritas na tabela 3, em especial, PUC-SP, UFRJ, UFPB, UFES e UERJ, embora o predomínio seja nitidamente de autores vinculados a instituições do Estado de Minas Gerais (Tabela 5). O que fica evidente, nessas informações, é a relação quase direta entre a posição ocupada por alguns desses pesquisadores na direção do corpo editorial da revista e o número de trabalhos publicados. Igualmente, grande parte dos autores que publicaram mais de dois trabalhos nessa fase estavam envolvidos com a organização da ABRAPSO.

Tabela 5 - Descrição dos autores com três, ou mais, trabalhos na primeira fase da revista (1986 -1992)

\begin{tabular}{|c|c|c|}
\hline Autores e Instituição & $\begin{array}{l}\text { Frequência } \\
\text { de trabalhos }\end{array}$ & $\%$ \\
\hline $\begin{array}{l}\text { Elizabeth de Melo Bonfim - } \\
\text { UFMG }\end{array}$ & 28 & 10,3 \\
\hline $\begin{array}{c}\text { Maria Novais da Mata Machado } \\
\text { - UFMG }\end{array}$ & 13 & 4,8 \\
\hline Edson A. de Souza - UFRJ & 9 & 3,3 \\
\hline Karin Von Smigay - UFMG & 7 & 2,6 \\
\hline Lucia Afonso - UFMG & 5 & 1,8 \\
\hline Keila Deslandes - UFMG & 4 & 1,5 \\
\hline Angela Caniato - UEM & 4 & 1,5 \\
\hline Welber da Silva Braga - UFMG & 3 & 1,1 \\
\hline Sonia Roedel - UFSJ & 3 & 1,1 \\
\hline Silvia Lane - PUC-SP & 3 & 1,1 \\
\hline Rui Barbosa - UFSJ & 3 & 1,1 \\
\hline $\begin{array}{l}\text { Marilene Coura Nascimento - } \\
\text { S/l }\end{array}$ & 3 & 1,1 \\
\hline Maria Lucia Volante - S/I & 3 & 1,1 \\
\hline $\begin{array}{l}\text { Maria Elizabeth Barros de } \\
\text { Barros }\end{array}$ & 3 & 1,1 \\
\hline Marcos Vieira Silva - UFSJ & 3 & 1,1 \\
\hline Marcia Midori Watanabe - S/I & 3 & 1,1 \\
\hline $\begin{array}{c}\text { Lizaynny A. Alves Queiroz - } \\
\text { UFMG }\end{array}$ & 3 & 1,1 \\
\hline
\end{tabular}

Em relação ao padrão de autoria, nota-se um número elevado de trabalhos publicados em individualmente (Tabela 6) - quase $80 \%$ dos trabalhos -, seguidos por $11,4 \%$ de trabalhos publicados em coautoria - dois autores e 4,4\% de trabalhos publicados - três autores. Observa-se, dessa maneira, um número relativamente pequeno de trabalhos publicados em coautoria. A organização ainda incipiente da disciplina, com poucos programas de pós-graduação, e o elevado volume de trabalhos teóricos são, provavelmente, alguns motivos que justificam o baixo número de coautorias. Além disso, deve-se levar em consideração que a lógica de coautoria na área seja um efeito mais evidente e provocado pelas alterações na lógica de produção de conhecimento na área a partir de meados da década de 1990, quando se identifica um aumento gradual e constante desse padrão de autoria (Cruz, 2008) ${ }^{1}$. 
Tabela 6 - Padrão de autoria na primeira fase da revista (1986 -1992)

\begin{tabular}{ccc}
\hline $\begin{array}{c}\text { Número de autor (es) por } \\
\text { trabalho }\end{array}$ & $\begin{array}{c}\text { Frequência } \\
\text { de trabalhos }\end{array}$ & $\%$ \\
\hline 1 & 218 & 78,7 \\
2 & 31 & 11,2 \\
3 & 12 & 4,3 \\
4 & 6 & 2,2 \\
5 & 5 & 1,8 \\
6 & 2 & 0,7 \\
7 & 1 & 0,4 \\
8 & 2 & 0,7 \\
\hline Total & 277 & 100 \\
\hline
\end{tabular}

Outro dado levantado foi a participação de profissionais de outras áreas do conhecimento nos trabalhos publicados na revista (Tabela 7). Esse tipo de informação pode revelar a interação da comunidade com outras áreas do conhecimento. No entanto, o formato da revista, nesse período, não possibilitou que fossem feitas afirmações confiáveis sobre o número exato da participação de profissionais de outras áreas. Em muitos trabalhos, não foi possível identificar a formação dos autores, portanto os dados devem ser considerados apenas parciais.

Tabela 7 - Profissionais de outras áreas na primeira fase da revista (1986-1992)

\begin{tabular}{ccc}
\hline Profissão & Frequência de trabalhos & $\%$ \\
\hline Médico & 5 & 1,8 \\
Engenheiro & 4 & 1,5 \\
Sociólogo & 2 & 0,7 \\
Antropólogo & 1 & 0,4 \\
Fonoaudióloga & 1 & 0,4 \\
Educadora & 1 & 0,4 \\
Fotógrafo & 1 & 0,4 \\
\hline Total & 15 & 5,5 \\
\hline
\end{tabular}

Assim, a partir da descrição nos próprios trabalhos, foram identificados profissionais de sete áreas distintas do conhecimento, a saber: profissionais da área da saúde; ciências sociais; ciências sociais aplicadas; educação e arte. Na leitura dos trabalhos desses profissionais também se observou que a sua participação ocorreu, sobretudo, em função de convites das comissões organizadoras dos eventos da ABRAPSO.

\section{Tipos e temáticas dos trabalhos}

A primeira fase da revista apresenta um total de 277 artigos. Um dado expressivo dessa fase diz respeito ao elevado número de trabalhos classificados como "Estudos Teóricos" - mais de 50\%. Uma informação, desde já importante, para se compreender esse dado, diz respeito aos seus objetivos, que foram, em geral, os de definir conceitos e práticas da área. Já os relatos de pesquisas e experiências acadêmicas e profissionais correspondem, respectivamente, a $22,4 \%$ e $21,7 \%$ dos trabalhos publicados nessa fase. Trabalhos classificados como outros (contos, poemas, informes etc.) representaram $2,9 \%$ dos trabalhos.

Em relação às temáticas apresentadas nos trabalhos, observou-se uma diversidade de temas (Tabela 8), embora seja preciso dizer que a própria estrutura dessa informação apresentou várias limitações. A primeira diz respeito à impossibilidade de criação de categorias excludentes, ou seja, em muitos casos, um trabalho envolvia mais de uma temática. Para tentar amenizar esse problema, o critério geral para escolher em qual temática alocar um determinado trabalho foi o tema geral estabelecido a partir do título do artigo. Quando, a partir desse critério, não foi possível definir a temática, realizou-se uma leitura do resumo ou do texto, de forma a facilitar a sua identificação. Além disso, utilizaram-se os trabalhos de Bomfim (1989) e Zanella (1994), que realizaram estudos preliminares sobre as temáticas veiculadas na revista Psicologia \& Sociedade na década de 80 e início dos anos 90. Assim, recorreu-se a alguns dados já organizados por essas autoras e às categorias já criadas por elas. A Tabela 8 apresenta a distribuição geral das temáticas.

Tabela 8 - Distribuição dos trabalhos por temáticas apresentadas na primeira fase da revista (1986 -1992)

\begin{tabular}{ccc}
\hline $\begin{array}{c}\text { Temáticas dos trabalhos } \\
\text { veiculados na primeira fase }\end{array}$ & Frequência & $\%$ \\
\hline $\begin{array}{c}\text { Aspectos Teóricos e Históricos } \\
\text { Psicologia e Comunidade }\end{array}$ & 29 & 10,5 \\
(Psicologia Comunitária) & 28 & 10,1 \\
Movimentos Sociais & 25 & 9,0 \\
Gênero e Sexualidade & 23 & 8,3 \\
Trabalho & 18 & 6,5 \\
Estudos em Representação & 16 & 5,8 \\
Social & 16 & 5,8 \\
Intervenção e Interpretação de & 15 & 5,4 \\
Fenômenos Psicossociais & 15 & 5,4 \\
Educação & 14 & 5,1 \\
Saúde Pública/Saúde Mental & 14 & 5,1 \\
Grupos & 11 & 4,0 \\
Formação e Ensino & 9 & 3,2 \\
Arte e literatura & 8 & 2,9 \\
Identidade & 8 & 2,9 \\
Análise Institucional & 5 & 1,8 \\
Metodologia e Técnica & 23 & 8,3 \\
\hline Comunicação & 277 & 100 \\
\hline Temáticas Variadas & &
\end{tabular}


A primeira área temática, "Aspectos Teóricos e Históricos", foi a mais representativa na primeira fase da revista, com cerca de $10 \%$ do total de trabalhos. Mas, como abordado anteriormente, as informações acerca das temáticas impuseram uma série de limitações. Dessa forma, a contabilização geral de trabalhos teóricos é, com certeza, maior do que a descrita acima. Isto porque, em praticamente todas as demais categorias, como, por exemplo, "Psicologia e Comunidade" e "Movimentos Sociais", entre outras, houve trabalhos, voltados para a definição teórica básica desses campos e conceitos.

Os objetivos desses trabalhos foram, principalmente, apresentar definições didáticas introdutórias dos diversos campos de pesquisa e atuação da Psicologia Social. Não é por acaso que títulos como: "O que é psicologia comunitária", "O que é análise institucional" e "O que é movimentos sociais" compuseram expressiva parte dos trabalhos classificados como "Estudos Teóricos". O que fica evidente nos trabalhos é a preocupação em descrever, da maneira mais clara e direta possível, as formas de atuação, os conceitos e as diversas áreas da Psicologia Social. Já nos trabalhos históricos, prevaleceram descrições históricas sobre as transformações da Psicologia Social naquele momento, e como uma nova perspectiva crítica emergia naquela fase. Também foram identificadas descrições históricas acerca do surgimento da ABRAPSO.

Nos trabalhos da segunda temática, "Psicologia e Comunidade", que correspondem a $10,1 \%$ do total de trabalhos publicados na revista, foi possível notar a preocupação dos autores em descrever experiências de trabalhos comunitários e as diversas possibilidades de atuação da Psicologia Social em comunidades desfavorecidas socialmente. Experiências envolvendo reivindicações de organizações comunitárias, como associações de moradores e moradores de zonas rurais, que buscavam algum tipo de melhoria básica para aquela região e/ou grupo, como saúde e saneamento básico, são alguns exemplos. Trabalhos voltados para reflexões críticas sobre o papel da Psicologia Comunitária também foram publicados.

"Movimentos Sociais" foi a terceira temática com maior representatividade, com vinte e cinco trabalhos, que correspondem a $9 \%$ do total. Duas informações que chamam a atenção, nessa categoria, são o número de trabalhos voltados para a análise de mobilizações populares - cinco no total - e as discussões críticas sobre a relação entre psicologia e movimentos sociais - quatro trabalhos. Os demais trabalhos apresentam análises acerca do movimento de trabalhadores rurais, movimento ecológico, entre outros.

A temática "Gênero e Sexualidade" apresentou vinte e três trabalhos, que corresponderam a $8,3 \%$ do total. A característica principal desses trabalhos foi a descrição de investigações acerca do papel e da situação da mulher em contextos diversos. Os novos papéis da mulher na vida conjugal, a mulher e sua imagem na mídia, as formas de emancipação da mulher, a mulher e os conflitos da reprodução e a exclusão social da mulher, foram os temas tratados. No caso do gênero masculino, destacam-se três investigações sobre a paternidade na contemporaneidade. Os demais trabalhos tratam, em especial, da relação entre a Psicologia e os estudos de gêneros e suas definições básicas.

A temática "Trabalho" foi a quinta com o maior número de trabalhos publicados. Nessa fase da revista foram identificados dezoito trabalhos, correspondendo a $6,5 \%$ do total das investigações publicadas. Diferentemente das temáticas anteriores, o que se observou foi a inexistência de concentração de trabalhos em alguma subtemática específica. Na verdade, foi a diversidade de temáticas dos trabalhos que chamou a atenção nesse caso. Foram identificados, por exemplo, desde trabalhos relacionados à ergonomia até pesquisas voltadas para o labor rural.

A criação da sexta temática, "Estudos em Representação Social", necessita de uma breve explanação do porquê de sua formulação, já que essa é considerada mais uma abordagem do que uma temática específica da Psicologia Social. A criação de uma categoria específica para os estudos nesse campo justifica-se pelo elevado número de trabalhos que tiveram como base o conceito de representação social: dezesseis publicações, que correspondem a 5,8\% do total. Assim, parece ser relevante destacar os estudos orientados por essa perspectiva, já que ela indica uma nova tendência nos estudos em Psicologia Social nesse momento.

As investigações, nessa área, versaram sobre diversas questões, como a representação social de Brasília e da Baixada Fluminense; investigações realizadas a partir da população daquelas cidades. A representação social de eleitores acerca dos candidatos à Presidência da República e a representação social do saber científico são outros exemplos de trabalhos que compuseram essa temática, além de três trabalhos que tiveram como objetivo discutir a definição conceitual de representação social.

Também com 5,8\% de representatividade, a "Intervenção e Interpretação de Fenômenos Psicossociais" foi a sétima temática considerada nessa fase. A construção dessa temática teve como base a categorização de trabalhos especialmente voltados para a interpretação de macros fenômenos psicossociais. Desse modo, apenas três dos dezesseis trabalhos dessa temática foram designados como de intervenção: um trabalho de intervenção psicossocial em um sindicado e outros dois sobre a definição de intervenção psicossocial. Os demais trabalhos tiveram como foco análises e interpretações 
de fenômenos diversos. Análises do acidente nuclear na cidade de Goiânia, de problemas ambientais, discussões acerca dos problemas psicossociais da criminalidade, comportamentos de massa e de consumo foram alguns dos trabalhos que constituíram essa temática. Um aspecto importante a ser considerado acerca dessa temática é o esforço dos autores para estabelecer uma análise de fenômenos considerados somente de ordem sociológica e, portanto, vistos, muitas vezes, fora do campo da psicologia.

"Educação", com 5,4\% dos trabalhos publicados, foi outra temática identificada na primeira fase da revista. As publicações nesse campo tiveram como subtemáticas as seguintes questões: a relação entre a psicologia e o papel do psicólogo no contexto escolar, o papel da Psicologia Social na escola, teorias utilizadas para o trabalho do psicólogo na escola, processo de escolarização de classes populares, entre outros. Nesse caso, a diversidade de temas também foi a característica marcante.

"Saúde mental/Saúde Pública" teve um número significativo de trabalhos publicados na revista - 5,4\% dos trabalhos. Representaram essa temática as discussões acerca do papel do psicólogo em instituições de saúde mental, a luta antimanicomial, as políticas para deficientes mentais e a definição de conceitos como o de saúde mental. Já os trabalhos em saúde pública tiveram como foco a organização do sistema público de saúde e a participação da população em conselhos de saúde pública. Com uma representação próxima à dessa categoria, 5,1\% , a temática "Formação e Ensino" demonstra a preocupação da área com questões como: a estrutura curricular do curso de Psicologia, a extensão universitária, os estágios supervisionados e as dificuldades e práticas no ensino da Psicologia Social.

Também com $5,1 \%$ de participação, a temática "Grupos" revela uma série de obras voltadas para a compreensão da dinâmica de funcionamento de pequenos grupos. Grupos de universitários, funcionários de instituições públicas e rituais de grupos religiosos compuseram os focos desses trabalhos. Além disso, relatos sobre estágios supervisioinados e metodologia de trabalhos com grupos foram publicados.

Uma temática que necessita ser destacada, nessa fase da revista, é "Psicologia, Arte e Literatura", que correspondeu a $4 \%$ da frequência de trabalhos publicados. Nesse caso, os trabalhos foram apresentados em formato de contos e poemas. Problemas psicossociais, como a descrição de uma experiência de trabalho na favela, por meio de um conto, ou uma análise crítica do trabalho psicológico, por meio de um poema, expõem novas maneiras de olhar para essas questões.

A categoria "Análise Institucional", $\operatorname{com} 2,9 \%$ dos trabalhos, é caracterizada pelas descrições de análises institucionais, especialmente no campo da educação para menores infratores. Também foi identificado um artigo teórico que apresenta uma introdução ao conceito de análise institucional.

Discussões sobre o uso de entrevistas em pesquisas, a análise gráfica do discurso, as técnicas de intervenção e o método experimental corresponderam a 2,9\% da frequência de trabalhos e foram classificados como "Metodologia e Técnicas". "Comunicação", com $1,8 \%$ dos trabalhos, buscou estabelecer a relação entre psicologia e comunicação de massa, bem como os usos da mídia, as análises de conteúdo televisivo e jornalístico por psicólogos sociais.

Por fim, 8,9\% das publicações foram classificadas como "Temáticas Variadas", categoria criada para aqueles trabalhos que não tiveram classificação nas demais temáticas. Nesse grupo, enquadram-se trabalhos diversos, que vão de pesquisa sobre etiologia e a definição de comportamento social, até o relato de uma expedição ao interior de Minas Gerais.

\section{Caracterização das pesquisas, experiências e relatos de intervenções}

Nesse item, expõe-se a descrição de alguns dados gerais acerca dos trabalhos classificados como "Relato de Pesquisa" e "Relato de Experiência", apresentados na primeira fase da revista. A função dessa caracterização foi conhecer as tendências metodológicas, o público investigado e os locais de realização de pesquisa e intervenções nos trabalhos publicados na primeira fase da revista.

No entanto, ocorreu uma série de dificuldades para se organizar essas informações. A primeira delas está relacionada ao formato da revista. Nesse período, muitos trabalhos, que foram denominados como de pesquisa ou intervenção, não apresentaram, em seu conteúdo, as informações necessárias para uma análise mais apurada. São citados, por exemplo, os participantes da pesquisa, mas não o instrumento e/ou procedimentos de coleta de dados, ou vice-versa. Esse fato não se deve, necessariamente, à qualidade da revista, mas ao formato e às condições de produção da mesma naquele período.

As informações acerca dos participantes e dos locais de realização das pesquisas e demais trabalhos, descritos como experiência ou intervenção, foram expostos de maneira conjunta. Essa decisão foi tomada tendo em vista que esses dados fazem parte de ambos, "Relato de Pesquisas" e "Relato de Experiências". Além disso, a categorização das informações foi realizada de forma que refletisse a denominação feita pelos próprios autores. Esse critério de categorização teve como objetivo a tentativa de descrever, da forma mais próxima 
possível, a concepção dos autores acerca do contexto e das pessoas envolvidas nas pesquisas e intervenções, $o$ que pode ser útil para observar possíveis mudanças na utilização da própria nomenclatura usada pelos autores e, por conseguinte, mudanças de concepções sobre o contexto de investigação e público investigado.

A primeira descrição diz respeito ao delineamento das pesquisas. Como pode ser observado na Tabela 9, uma característica marcante das pesquisas é a recorrência a métodos qualitativos.

Tabela 9 - Descrição dos delineamentos de pesquisa na primeira fase da revista (1986-1992)

\begin{tabular}{ccc}
\hline Delineamento de pesquisa & Frequência & $\%$ \\
\hline Qualitativa & 51 & 82,3 \\
Qualitativa e Quantitativa & 7 & 11,3 \\
Quantitativa & 2 & 3,2 \\
Experimental & 2 & 3,2 \\
\hline Total & 62 & 100 \\
\hline
\end{tabular}

Mais de $80 \%$ dos trabalhos classificados como relatos de pesquisa foram de cunho qualitativo e envolveram o uso de alguma metodologia, baseada nessa perspectiva. Nota-se, ao mesmo tempo, um número bastante reduzido de trabalhos que recorreram a metodologias conjuntas, no caso qualitativas e quantitativas, e menos ainda trabalhos designados como quantitativos e experimentais.

Tabela 10 - Procedimentos, fonte e técnicas de coleta de informações nas pesquisas

\begin{tabular}{ccc}
\hline $\begin{array}{c}\text { Tipo de procedimento, fonte e } \\
\text { técnica de coleta de dados }\end{array}$ & Frequência & $\%$ \\
\hline Entrevista semiestruturada & 10 & 16,1 \\
Questionário & 7 & 11,3 \\
Entrevista semiestruturada e & 7 & 11,3 \\
questionário & 6 & 9,7 \\
Documentos & 5 & 8,1 \\
Diário de Campo & 2 & 3,2 \\
Fotografia & 1 & 1,6 \\
Questionário e diário de campo & 1 & 1,6 \\
Entrevista semiestruturada e & 1 & 1,6 \\
Fotografia & 22 & 35,5 \\
Inventário & 62 & 100,0 \\
\hline Sem informação & & \\
\hline Total & &
\end{tabular}

A descrição dos procedimentos, técnicas e materiais utilizados para a coleta de informações nas pesquisas da primeira fase complementam a descrição anterior, pois, em geral, os procedimentos são caracterizados pela busca de informações qualitativas (tabela
10). Nesse caso, observa-se a recorrência, em especial, de instrumentos de coleta de dados adequados a este enfoque metodológico. A entrevista semiestruturada apresentou-se como a técnica mais utilizada.

É necessário dizer que, por meio da leitura dos resumos e trabalhos completos, foi identificada de maneira expressiva a utilização de metodologias que envolviam alguma forma de pesquisa participante. Essa informação não foi apresentada de maneira quantificada, já que os autores não descreveram explicitamente a sua utilização. Contudo, parece relevante destacá-la, tendo em vista que ela indica o elevado uso de uma perspectiva metodológica nos estudos e intervenções em Psicologia Social naquela fase de transição.

Os locais de realização das pesquisas e intervenções foi outra informação considerada relevante para se caracterizar os trabalhos desse período, porque a identificação dessas informações indica os contextos de investigações e a atuação dos psicólogos sociais. Mas é preciso dizer que mais de $50 \%$ dos locais de realização das pesquisas e intervenções não foram identificados porque os autores não fizeram referência a essa informação. E, mesmo sendo necessária a criação de um número elevado de categorias, optou-se por organizar essas informações, como já mencionado, a partir da denominação realizada pelos próprios autores. Desse modo, ao invés de criar uma categoria que incluísse, por exemplo, Periferia e Favela, decidiu-se manter essas denominações em categorias separadas.

No total, foram identificados quinze locais de realização dos trabalhos. A "Universidade" apresenta-se como o local onde ocorreu o maior número de pesquisas e intervenções, um total de nove, que corresponde a 7,4\% dos locais. Também se observou a concentração de trabalhos realizados em bairros periféricos, comunidades rurais, favelas, vias públicas e instituições para menores (Tabela 11). Ao mesmo tempo, locais considerados tradicionais nos estudos da psicologia, como escolas, indústrias e hospitais, fazem parte do interesse dos psicólogos sociais que publicaram seus trabalhos nessa fase da revista.

Tabela 11 - Locais de realização das pesquisas e intervenções na primeira fase da revista (1986 -1992)

\begin{tabular}{ccc}
\hline Local & $\begin{array}{c}\text { Frequên- } \\
\text { cia }\end{array}$ & $\%$ \\
\hline Universidade & 9 & 7,4 \\
Periferia & 8 & 6,6 \\
Comunidade Rural & 7 & 5,7 \\
Favela & 7 & 5,7 \\
Escola & 7 & 5,7 \\
Via pública & 4 & 3,3 \\
Delegacia & 3 & 2,5
\end{tabular}




\begin{tabular}{ccc} 
Instituição para menores & 3 & 2,5 \\
Igreja & 2 & 1,6 \\
Indústria & 2 & 1,6 \\
Posto de Saúde & 2 & 1,6 \\
Sindicado & 2 & 1,6 \\
Banco & 1 & 0,8 \\
Hospital & 1 & 0,8 \\
Prefeitura & 1 & 0,8 \\
Sem informação & 63 & 51,6 \\
\hline Total & 122 & $\mathbf{1 0 0 , 0}$ \\
\hline
\end{tabular}

A última descrição dessa fase refere-se às características dos participantes envolvidos nos trabalhos publicados (Tabela 12). Participantes escolhidos em função de sua atividade profissional ou de trabalho constituíram o maior grupo em pesquisas e intervenções - 14,8\%. No geral, a escolha desses participantes teve como objetivo possibilitar investigações preocupadas em analisar a saúde mental do trabalhador e os contextos geradores de sofrimento mental.

Tabela 12 - Participantes das pesquisas e intervenções na primeira fase da revista (1986 -1992)

\begin{tabular}{ccc}
\hline Participantes & Frequência & $\%$ \\
\hline $\begin{array}{c}\text { Trabalhadores e participantes } \\
\text { escolhidos em função de sua } \\
\text { atividade profissional }\end{array}$ & 18 & 14,8 \\
Adolescentes e crianças & 8 & 6,6 \\
Estudantes Universitários & 8 & 6,6 \\
Moradores de periferia e favela & 7 & 5,7 \\
Mulheres & 4 & 3,3 \\
Moradores de Zona Rural & 3 & 2,5 \\
Participantes diversos & 11 & 9,0 \\
Sem informação & 63 & 51,6 \\
\hline Total & 122 & 100 \\
\hline
\end{tabular}

Os participantes classificados como "Adolescentes e Crianças" aparecem em segundo lugar no total, o que corresponde a $6,6 \%$ dos trabalhos apresentados como pesquisas e/ou intervenções. As características desse público apontam, em particular, para adolescentes inseridos em comunidades desfavorecidas socialmente e instituições, como escolas públicas, instituições para menores infratores e locais como ruas de centros urbanos. "Estudantes Universitários" constituíram 6,6\% dos participantes envolvidos nos trabalhos veiculados na revista, no referido período. A escolha desse público esteve relacionada diretamente à sua posição perante temas diversos e ao contexto acadêmico.
A participação de "Moradores de Periferia e Favela", 5,7\%, e "Moradores de Zona Rural", 2,5\%, sugestiona a atuação da psicologia comunitária e sua inserção em ambientes de pobreza e exclusão social. Em seguida, observou-se a escolha de "Mulheres", 3,3\%, como participantes de pesquisas e intervenções. Nesse caso, notou-se uma preocupação com a inserção das mulheres em espaços como o mercado de trabalho e a universidade e, também, com problemas vivenciados pelas mulheres na área da saúde e em contextos onde a violência contra elas é trabalhada, como em delegacias de crimes contra a mulher.

Por fim, os "Participantes Diversos", 9\%, não deixam de ser importantes, já que sinalizam a preocupação de alguns pesquisadores em investigar e intervir na realidade de indivíduos e/ou grupos vítimas de preconceitos como, por exemplo, homossexuais, afro-descendentes, dentre outros. Todavia, é preciso recordar que o grande número de trabalhos que não especificou essa informação dificultou uma descrição mais apurada e representativa.

\section{Considerações finais}

Antes de tecer algumas considerações finais, é necessária a explicitação de algumas limitações da presente investigação, devido, em especial, ao perigo de generalizações diretas das informações apresentadas. Assim, acerca das informações descritas, mesmo que de modo incipiente, é provável que, em muitos pontos, seja quase inevitável para o leitor, assim como foi para os autores, a tentação de fazer generalizações para o contexto geral da Psicologia Social brasileira. Todavia, as informações sobre as temáticas dos trabalhos, por exemplo, e outras informações descritas neste trabalho, não podem ser consideradas representativas de toda a produção do conhecimento em Psicologia Social no Brasil naquela fase. Isto porque importantes produções no campo podem ter sido publicadas em outros meios de comunicação daquele período como livros e outras revistas de psicologia e/ou áreas afins.

Outro equívoco seria pensar que a Psicologia Social, no Brasil, reduz-se à Psicologia Social dos psicólogos vinculados, de uma forma ou de outra, à ABRAPSO. Portanto, mesmo que a revista Psicologia \& Sociedade seja um elemento importante da área, ela é apenas parte da história. Assim, ela nos dá somente indícios para uma interpretação parcial do funcionamento e da organização da Psicologia Social brasileira. Todavia, isso também não quer dizer que as informações foram insuficientes e/ou não permitiram generalizações, mesmo que razoáveis.

A relação direta entre contexto social, político e econômico e as condições para a produção de conheci- 
mento, no Brasil, constituiu um dos principais aspectos, passível de generalização, principalmente no que diz respeito ao acúmulo da produção em estados da região sudeste. O que se deve, ao fato de que a produção científica, em Psicologia Social, parece seguir premissas bem aceitas nos estudos sociais da ciência, como o pressuposto de que a ciência tem uma dimensão que funciona de acordo com uma espécie de economia de mercado. Nesse caso, o modelo econômico da ciência, apontado por Bourdieu (1983) e o de Efeito Matheus, sugerido por Merton (1973), indicam que aqueles que mais possuem vantagens tendem a ter mais probabilidade de acumular e conseguir benefícios no universo acadêmico, lembrando que uma das consequências desse efeito seria a disfuncionalidade na distribuição de crédito, na carreira de alguns pesquisadores. Isso sugere que a comunidade científica não está imune aos princípios mercantilistas. No caso deste trabalho, mesmo que sem aprofundar este aspecto, a organização social da Psicologia Social, assim como das demais áreas do conhecimento científico brasileiro, reflete, em alguma medida, os desequilíbrios regionais da produção técnico-científica, algo que, como sinalizou Barros (2000), perpassa toda a ciência brasileira ${ }^{2}$. Ao discutir os desequilíbrios regionais da produção técnico-científica, esse autor afirma que $82 \%$ dos grupos de pesquisa em atividade, no país, encontram-se nas regiões sudeste e sul e afirma que os recursos humanos qualificados como infraestrutura, e os recursos públicos federais, são canalizados para essas regiões. Para o autor, essas são apenas algumas das consequências das políticas científicas que funcionam de maneira semelhante às demais políticas nacionais, que tendem a beneficiar as regiões economicamente desenvolvidas do país. Em consonância com essa análise, Costa (2006) sugere que:

o traço característico brasileiro de diferenças regionais não se dá apenas no plano sócio-econômico, mas também no desenvolvimento científico e tecnológico. Tal acentuado desnível regional da base técnico-científica se apresenta nos mais diversos aspectos: qualificação dos recursos humanos, existência de centros de pesquisa, adequação da infraestrutura e investimentos financeiros. (Costa, 2006, p. 17)

Essa análise, embora se refira ao contexto recente da ciência no Brasil, na presente investigação parece fazer sentido e serve, sobretudo, para pensarmos a situação da pesquisa em Psicologia Social nas regiões norte e nordeste durante a década de 1980, quando acesso a financiamentos e programas específicos de desenvolvimento científico praticamente eram inexistentes para essas regiões.

Sobre o padrão de autoria, destaca-se a prevalência de trabalhos publicados apenas por um autor, o que pode ser resultado da elevada quantidade de trabalhos teóricos, dos quais uma das principais características é o padrão de autoria individual. Outra informação importante diz respeito à dispersão dos autores que, em sua maioria, publicaram apenas um trabalho. $\mathrm{O}$ que pode ser devido ao fato da revista nesse momento ser uma divulgação dos anais dos encontros regionais e nacionais da ABRAPSO. No entanto, destacamos a concentração de autores que publicaram mais de quatro trabalhos na revista. Além de serem pesquisadores ativos no campo, outro aspecto a ser considerado é que praticamente todos esses autores participaram diretamente da organização da revista e dos encontros da ABRAPSO no período descrito.

Sobre o conteúdo temático apresentado na revista, chama a atenção, entre outras coisas, a grande quantidade de trabalhos teóricos que buscam novas definições para conceitos e práticas dos psicólogos sociais. Não é por acaso que vários artigos foram intitulados como " $\mathrm{O}$ que é psicologia social", entre outros títulos semelhantes. Ao mesmo tempo, não deixa de ser relevante notar como as demais temáticas e subtemáticas representam novos contextos de atuação do psicólogo social e temas pouco estudados até então pela disciplina no Brasil (Bonfim, 2003).

Sobre os aspectos metodológicos, a afirmação mais relevante diz respeito ao tipo de delineamento de pesquisa descrito. Mais de $80 \%$ desses trabalhos apresentam sua metodologia como qualitativa. Supõe-se que tal informação reflita, também, uma importante mudança de perspectiva teórica e metodológica da Psicologia Social. Isso porque uma das principais críticas à Psicologia Social que vinha sendo praticada nas décadas anteriores apontava para o excesso de quantificação e experimentação nos estudos dos fenômenos psicossociais. Nessa perspectiva, as alegações de que os métodos quantitativos haviam sido formulados em contextos sociais diversos ao latino-americano vinham acompanhadas de críticas sobre a forma descontextualizada de como esse tipo de metodologia era utilizada (Bonfim, 2003; Lane, 1981), o que acarretava problemas de ordem metodológica, epistemológica, ética, ideológica e política.

A proposta do presente estudo foi uma descrição de elementos que perpassam mudanças nos rumos da produção e organização social de parte significativa da Psicologia Social brasileira a partir do início da década de 1980. Todavia, a sensação é de termos apenas tocado em questões amplas e complexas. Desse modo, é possível dizer que cada informação tratada aqui apresenta possibilidades de desdobramentos em outras pesquisas e análises mais complexas. Por isso, a busca por uma investigação acerca da produção de conhecimento em Psicologia Social, no Brasil, indica mais a possibilidade de um início de programa de pesquisa voltado para a 
compreensão de sua organização social e científica do que, necessariamente, afirmações fechadas. Mais de três décadas separam o presente das discussões acerca da chamada crise da Psicologia Social no contexto brasileiro e latino-americano e, embora 30 anos representem pouco tempo em termos históricos, no caso da Psicologia Social brasileira parece prover condições suficientes para análises críticas sobre sua organização e funcionamento.

\section{Notas}

1 Na análise da segunda fase da revista, que é composta pelo período de 1996 a 2007, quando o formato da revista adquire as características dos periódicos científicos tradicionais, nota-se um aumento exponencial de artigos publicados por dois ou mais autores. Dentre as possíveis interpretações para esse fenômeno, destacamos o surgimento de novos programas de pós-graduação e como isso passa a propiciar condições para publicação de dois ou mais autores, mas também ressaltamos o início da avaliação da produção científica da pós-graduação em psicologia, no Brasil, e o fato de que um dos principais critérios dessa avaliação seja o número de artigos científicos publicados, avaliação que começa a ser realizada justamente no ano de 1996, ano e início da segunda fase da revista.

2 Na análise da segunda fase da revista essa tendência prevalece. Mais de $80 \%$ dos trabalhos são oriundos de instituições das regiões sul e sudeste.

\section{Referências}

ABRAPSO - Associação Brasileira de Psicologia Social. (1995). Estatuto. Acesso em 10 de janeiro, 2011, em http://www. abrapso.org.br/conteudo/view?ID_CONTEUDO=547 .

Arruda, A., Baptista, L.A., Nascimento, L. M., Rocha-Coutinho, M. L. \& Jurberb, M. B. (1992). Editorial. Psicologia \& Sociedade, 7(10), 1-5.

Barros, F. A. F. (2000). Os desequilíbrios regionais da produção técnico-científica. São Paulo em Perspectiva, 14(3), 12-19.

Bomfim, E. M. (1989-1990). A psicologia social da ABRAPSO. Psicologia \& Sociedade, 5(8), 219-225.

Bomfim, E. M. (2003). Psicologia social no Brasil. Belo Horizonte: Campo Social.

Bourdieu, P. (1983). O campo científico. In R. Ortiz, Pierre Bourdieu: Sociologia (pp. 122-155). São Paulo: Ática.

Costa, A. L. F. (2006). Publicação e avaliação de periódicos cientificos: paradoxos da classificação Qualis em Psicologia. Dissertação de Mestrado, Programa de Pós-graduação em Psicologia, Universidade Federal do Rio Grande do Norte, Natal, RN.

Caniato, A. (1986). Editorial. Psicologia \& Sociedade, 1(1), 1-2.

Elms, A. C. (1971). The crisis of confidence in social psychology. American Psychologist, 30(10), 967-976.
Faye, C. (2005). Gabriel Tarde, Émile Durkheim, and the chronic 'crisis' in social psychology. Unpublished master's thesis, York University, Toronto, Canada.

Irwin, S. (1971). Crisis in social psychology: the relevance of relevance. American Psychologist, 26(6), 583-584.

Kuhn, T. S. (1962). The structure of scientific revolutions. Chicago: University of Chicago Press.

Lane, S. (1981). O Que é Psicologia Social. São Paulo: Editora Brasiliense.

Lane, S.T.M. \& Codo, W. (1984). Psicologia Social: O homem em movimento. São Paulo, SP: Brasiliense.

Meadows, A. J. (1999) A comunicação científica. Brasília, DF: Briquet de Lemos.

Merton, R. K. (1973). The sociology of science: Theoretical and empirical investigations. London: University of Chicago.

Mitsui, H. (1986). What is the so-called "crisis in social psychology?". Japanese Journal of Experimental Social Psychology, 25(2), 171-176.

Molon, S. (2001). A psicologia social abrapsiana: apontamentos históricos. Interações, 6(12), 41-68.

Rodríguez, A. (1987). Psicologia social: perspectiva después de una crisis. Revista de Psicología General y Aplicada, 32(148), 849-862.

Zanella, A. V. (1994). Os 15 anos da ABRAPSO (Associação Brasileira de Psicologia Social): contribuições à produção e divulgação do conhecimento em Psicologia. In R. H. F. Campos \& E. M. Bonfim (Eds.), Anais do V Simpósio de Pesquisa e Intercâmbio Científico/ Anpepp (pp.23-29). Belo Horizonte.

Recebido em: 04/06/2010

Revisão em: 18/10/2010

Aceite em: 23/11/2010

Robson Nascimento da Cruz é Especialista em História da Ciência, Mestre em Psicologia pela Universidade Federal de Minas Gerais e Doutorando em psicologia pela mesma instituição. Endereço: Rua Agenor Alves, 68. Nazaré. Belo Horizonte/MG, Brasil. CEP 31990-040. Email: robsonncruz@ig.com.br

Cornelis Johannes van Stralen é Doutor em Ciências Sociais pela Universidade Utrecht, Holanda. Docente do Programa de Pós-graduação em Psicologia da Universidade Federal de Minas Gerais.

\section{Como citar:}

Cruz, R. N. \& Van Stralen, C. J. (2012). A produção do conhecimento na psicologia social brasileira: um estudo descritivo a partir da revista Psicologia \& Sociedade, 19861992. Psicologia \& Sociedade, 24(1), 227-239. 